ISSN 0103-8478

\title{
Modelagem hierárquica Bayesiana na avaliação de curvas de crescimento de suínos genotipados para o gene halotano
}

\author{
Hierarchical Bayesian modeling for the evaluation of growth \\ curves of pigs genotyped for the halothane gene
}

\author{
Leandro Roberto de Macedo $^{\mathrm{I}^{*}}$ Fabyano Fonseca e Silva $^{\mathrm{III}}$ Marcelo Ângelo Cirillo ${ }^{\mathrm{II}}$ \\ Moysés Nascimento ${ }^{\mathrm{I}}$ Débora Martins Paixão ${ }^{\mathrm{III}}$ Simone Eliza Facioni Guimarães ${ }^{\mathrm{III}}$ \\ Paulo Sávio Lopes ${ }^{\mathrm{II}}$ Jussara Aparecida dos Santos ${ }^{\mathrm{IV}}$ Camila Ferreira Azevedo
}

RESUMO

Para avaliar a influência do gene halotano sobre a curva de crescimento de suínos, bem como sua interação com o sexo do animal, foi proposta uma modelagem hierárquica Bayesiana. Nesta abordagem, os parâmetros dos modelos nãolineares de crescimento (Logístico, Gompertz e von Bertalanffy) foram estimados conjuntamente com os efeitos de sexo e genótipos do gene halotano. Foram utilizados 344 animais F2(Comercial $x$ Piau) pesados ao nascer, aos 21, 42, 63, 77, 105 e 150 dias. $O$ modelo Logístico foi aquele que apresentou melhor qualidade de ajuste por apresentar menor DIC (Deviance Information Criterion) que os demais. As amostras das distribuições marginais a posteriori para as diferenças entre as estimativas dos parâmetros do modelo Logístico indicaram que o peso dos machos à idade adulta com genótipo heterozigoto ( $\mathrm{Hal}^{\mathrm{Nn}}$ ) foi superior ao dos homozigotos $\left(\mathrm{Hal}^{N N}\right)$. A título de comparação, também foi considerada a abordagem frequentista tradicional, baseada em dois passos distintos, a qual, por apresentar um menor poder de discernimento estatístico, não mostrou diferenças significativas.

Palavras-chave: melhoramento, modelos não-lineares, síndrome do estresse suíno.

\section{ABSTRACT}

A hierarchical Bayesian modeling was used to evaluate the influence of halothane gene and its interaction with sex on pig's growth curves. Under this approach, the parameters from growth models (Logistic, Gompertz and von Bertalanffy) were estimated jointly with the effects of halothane gene and sex. A total of 344 F2 (Commercial x Piau) animals were weighted at birth, 21, 42, 63, 77, 105 and 150 days in life. The Logistic model has presented the best fit based on DIC (Deviance Information Criterion). Thus, the samples from marginal posterior distributions for the differences between the parameters estimates of Logistic model have indicated that the maturity weight of males with heterozygous genotypes ( $\left.\mathrm{Hal}^{\mathrm{Nn}}\right)$ was superior to males with homozygous genotypes $\left(\mathrm{Hal}^{N N}\right)$. In order to realize a comparison with the traditional methodology, the frequentist approach based on two distinct steps also was used, but there was not identified significant differences between growth curve parameter estimates from each group (combinations of halothane genotypes and sex).

Key words: improvement, nonlinear models, pig stress syndrome.

\section{INTRODUÇÃO}

Uma das estratégias adotadas na suinocultura para aumentar a eficiência da produção e melhorar a qualidade dos produtos foi o uso de genótipos especializados para ganho de peso. Devido ao aumento da frequência do alelo mutado do gene do estresse suíno (halotano) (FUJII et al., 1991) nas linhagens terminais selecionadas para produção, surgiram hipóteses de que este gene esteja diretamente relacionado com crescimento (SATHER et al., 1991; BRIDI et al., 2008). Animais com genótipos heterozigotos $\left(\mathrm{Hal}^{\mathrm{Nn}}\right)$ para o gene halotano são extremamente sensíveis ao estresse causado, por exemplo, pela mistura com outros animais, transporte, desmame e manejo (CULAU et al., 2002).

Alguns estudos, como o de BAND et al. (2005), foram realizados com o intuito de avaliar a influência do gene halotano sobre o peso dos animais em diferentes períodos de desenvolvimento, do desmame ao abate, porém nenhuma diferença

\footnotetext{
IDepartamento de Estatística, Universidade Federal de Viçosa (UFV), 36571-000, Viçosa, MG, Brasil. E-mail: leandro.macedo@ufv.br. *Autor para correspondência.

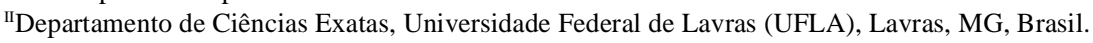

IIIDepartamento de Zootecnia, UFV, Viçosa, MG, Brasil.

${ }^{\text {IV }}$ Departamento de Fitotecnia, UFV, Viçosa, MG, Brasil. 
significativa foi encontrada. KUSEC et al. (2007) realizaram estudo pioneiro ao avaliar o efeito do gene halotano sobre as estimativas dos parâmetros do modelo Logístico ajustado a dados de pesoidade de animais cruzados (Pietrain $\times$ Hampshire e Large WhitexGerman). Estes autores utilizaram uma metodologia contemplando dois passos independentes, no primeiro, ajustou-se o modelo não-linear para dados individuais de peso-idade e, no segundo, as estimativas dos parâmetros provenientes desse ajuste foram consideradas como variáveis dependentes em um modelo linear (ANOVA), com efeito de gene halotano (com dois níveis: genótipos $\mathrm{Hal}^{\mathrm{NN}}$ e $\mathrm{Hal}^{\mathrm{Nn}}$ ). De acordo com BLASCO et al. (2003), algumas críticas a esta metodologia são: a estimação dos parâmetros e a estimação do efeito do gene são realizadas em duas etapas distintas, portanto a estimação dos parâmetros é realizada sem levar em consideração a diferença entre os animais quanto à presença do gene; na segunda etapa, as variáveis dependentes são estimativas de parâmetros de modelos não-lineares, portanto sujeitas à falta de normalidade requerida pela utilização de testes tradicionais como F e t-Student.

Segundo SILVA et al. (2005), em estudos envolvendo ajuste de modelos de regressão nãolinear a dados zootécnicos (curvas de crescimento e de lactação), a inferência Bayesiana pode ser utilizada com sucesso, pois reduz, substancialmente, o número de estimativas viesadas na presença de poucas observações, e fornece estimação por intervalo mais precisas em relação à obtida pela metodologia Frequentista. Além disso, sua principal vantagem é permitir que as estimativas dos parâmetros do modelo não-linear sejam estimadas simultaneamente com os efeitos de possíveis fatores que as afetam, isto é, sob o enfoque de modelagem hierárquica Bayesiana (SILVA et al., 2007). Esta modelagem permite ainda a comparação estatística direta e simplificada entre curvas provenientes de diferentes tratamentos por meio da obtenção de uma distribuição para as diferenças entre as estimativas dos parâmetros.

Diante do exposto, o principal objetivo do presente estudo foi investigar a influência do gene halotano sobre as estimativas dos parâmetros das curvas de crescimento de 344 animais (machos castrados e fêmeas) de uma população F2 (Comercial x Piau), considerando dados de pesagens do nascimento aos 150 dias de idade. Para tanto, foi proposta uma abordagem hierárquica Bayesiana contemplando três diferentes modelos de regressão não-linear (Logístico, Gompertz e von Bertalanffy). A título de comparação com a metodologia proposta, também foi empregada a análise frequentista tradicional baseada em dois passos distintos.

\section{MATERIAL E MÉTODOS}

Os dados utilizados são provenientes de 344 animais F2 (Comercial x Piau), machos castrados e fêmeas, da Granja de Melhoramento de Suínos do Departamento de Zootecnia da Universidade Federal de Viçosa (UFV). Os animais foram pesados nas seguintes fases de desenvolvimento: ao nascimento, aos 21, 42, 63, 77, 105 e 150 (abate) dias. As genotipagens para o gene halotano foram realizadas no Laboratório de Biotecnologia Animal (Labtec) do Departamento de Zootecnia (DZO) - UFV. Observouse que 149 machos e 141 fêmeas não eram portadores do alelo mutado do gene halotano $\left(\mathrm{Hal}^{\mathrm{NN}}\right)$, enquanto que 20 machos e 34 fêmeas eram portadores deste alelo $\left(\mathrm{Hal}^{\mathrm{Nn}}\right)$.

Independentemente da abordagem utilizada (Bayesiana ou frequentista), foram considerados os modelos de regressão nãolinear Gompertz $\left(y_{i j}=A_{i} e^{-b_{i} e^{-k_{i} t}}+\varepsilon_{i j}\right)$, Logístico ( $\left.y_{i j}=A_{i}\left(1+b_{i} e^{-k_{i} t}\right)^{-1}+\varepsilon_{i j}\right)$ e von Bertalanffy $\left(y_{i j}=A_{i}\left(1-b_{i} e^{-k_{i} t}\right)^{3}+\varepsilon_{i j}\right)$. Em todos estes modelos, $\mathrm{y}_{\mathrm{ij}}$ é o peso do animal i na idade $\mathrm{j}, \mathrm{A}_{\mathrm{i}}$ é a estimativa de peso na maturidade (peso adulto) do animal $i, b_{i}$ é o parâmetro de integração (não tem interpretação biológica, é uma constante matemática cuja função é ajustar o peso inicial em relação à origem) do animal $\mathrm{i}$ e $\mathrm{K}_{\mathrm{i}}$ é a taxa de maturidade (representa uma medida de precocidade, ou de velocidade de crescimento) do animal i, $\varepsilon_{\mathrm{ij}}$ é o termo de erro aleatório, considerado independente e identicamente distribuído, com distribuição normal com média zero e variância $\sigma_{\mathrm{e}}{ }^{2}$.

$\mathrm{Na}$ abordagem hierárquica Bayesiana, o efeito dos quatro grupos considerados (macho e fêmea com genótipos $\mathrm{Hal}^{\mathrm{NN}}$ e macho e fêmea com genótipos $\mathrm{Hal}^{\mathrm{Nn}}$ ) sobre as estimativas dos parâmetros das curvas de crescimento foram estimados separadamente para cada um dos três modelos considerados (Gompertz, Logístico e von Bertalanffy). No teorema de Bayes, a distribuição a posteriori dos parâmetros é proporcional ao produto da distribuição conjunta dos dados amostrais (função de verossimilhança) e das distribuições a priori para os parâmetros de interesse. Assumindo normalidade dos dados de crescimento, as funções de verossimilhança para os modelos Gompertz, Logístico e von Bertalanffy são dadas, respectivamente, por: 


$$
\begin{aligned}
& L\left(Y \mid \theta, \sigma_{e}^{2}\right) \propto \prod_{i=1}^{n} \prod_{j=1}^{n} \frac{1}{\sqrt{2 \pi \sigma_{e}^{2}}} \exp \left\{-\frac{\left[y_{i j}-A_{i}\left[1+\mathrm{b}_{\mathrm{i}} \exp \left(-K_{i} t_{i j}\right)\right]^{-1}\right]^{2}}{2 \sigma_{e}^{2}}\right\}, \\
& L\left(y \mid \theta, \sigma_{e}^{2}\right) \propto \prod_{i=1}^{n} \prod_{j=1}^{n} \frac{1}{\sqrt{2 \pi \sigma_{e}^{2}}} \exp \left\{-\frac{\left[y_{i j}-A_{i} \exp \left[-\mathrm{b}_{\mathrm{i}} \exp \left(-K_{i} t_{i j}\right)\right]\right]^{2}}{2 \sigma_{e}^{2}}\right\} \mathrm{e} \\
& L\left(y \mid \theta, \sigma_{e}^{2}\right) \propto \prod_{i=1}^{n} \prod_{j=1}^{n} \frac{1}{\sqrt{2 \pi \sigma_{e}^{2}}} \exp \left\{-\frac{\left[y_{i j}-A_{i}\left[1-\mathrm{b}_{i} \exp \left(-K_{i} t_{i j}\right)\right]^{3}\right]^{2}}{2 \sigma_{e}^{2}}\right\}
\end{aligned}
$$

Nas expressões (1), (2) e (3), o vetor $\theta$ representa os parâmetros $\mathrm{A}, \mathrm{b}$ e $\mathrm{K}$ para todos os indivíduos, além da variância do erro. No primeiro estágio da hierarquia, foram assumidas as seguintes distribuições a priori para os parâmetros dos modelos de crescimento: $A_{i} \sim N\left(\mu_{A}, \tau_{A}\right), b_{i} \sim N\left(\mu_{b}, \tau_{b}\right)$

e $K_{i} \sim N\left(\mu_{k}, \tau_{k}\right)$. No segundo e último estágio, foram especificadas as distribuições a priori para os parâmetros das distribuições assumidas no primeiro estágio. Tais distribuiçõos foram as seguintes:

$\mu_{A} \sim N\left(\mu_{\mu_{A}}, \tau_{\tau_{A}}\right), \quad \mu_{b} \sim N\left(\mu_{\mu_{b}}, \tau_{\tau_{b}}\right)$,

$\mu_{k} \sim N\left(\mu_{\mu_{k}}, \tau_{\tau_{k}}\right) \quad \tau_{A} \sim \operatorname{Gama}\left(\alpha_{A}, \beta_{A}\right)$

$\tau_{b} \sim \operatorname{Gama}\left(\alpha_{b}, \beta_{b}\right) \quad \tau_{k} \sim \operatorname{Gama}\left(\alpha_{k}, \beta_{k}\right)$ '

Além disso, especificou-se também uma distribuição a priori para a variância do erro:

$\sigma_{e}^{2} \sim \operatorname{Gama}\left(\alpha_{e}, \beta_{e}\right)$.Os valores dos hiperparâmetros

$\left(\mu_{\mu_{A}}, \tau_{\tau_{A}}, \mu_{\mu_{b}}, \tau_{\tau_{b}}, \mu_{\mu_{K}}, \tau_{\tau_{K}}, \alpha_{A}, \beta_{A}, \alpha_{b}, \beta_{b}, \alpha_{K}, \beta_{K}\right)$ foram escolhidos com base em análises prévias e em revisões de literatura.

A modelagem Bayesiana apresentada foi realizada no software $\mathrm{R}$ (R DEVELOPMENT CORE TEAM, 2012) através do pacote R2OpenBUGS, no qual foram implementados os algoritmos Gibbs sampler e o Metropolis-Hastings. Para avaliar a convergência, foram utilizados os testes de GEWEKE (1992) e RAFTERY \& LEWIS (1992) mediante o pacote Bayesian Output Analysis (boa) do R.

As amostras das distribuições marginais a posteriori para as diferenças entre as estimativas dos parâmetros A e K (aqueles com interpretação biológica direta) para cada um dos quatro grupos considerados foram obtidas com o intuito de verificar significância estatística por meio do intervalo HPD (Highest Posterior Density) de 95\%. Se o valor zero estiver contido neste intervalo, conclui-se que os parâmetros das duas populações envolvidas no contraste são estatisticamente iguais. Essa metodologia foi apresentada por SILVA et al. (2005) para comparar parâmetros de curvas de lactação de cabras referentes a duas diferentes populações, e posteriormente utilizada para comparar curvas de crescimento de gado Nelore de diferentes grupos genéticos (SILVA et al., 2007).

$\mathrm{Na}$ abordagem frequentista tradicional em dois passos, no primeiro, os modelos Gompertz, Logístico e von Bertalanffy foram ajustados para cada animal por meio do método dos quadrados mínimos ordinários, com soluções obtidas por meio do processo iterativo de Gauss-Newton, utilizando o pacote nls do R. No segundo passo, as estimativas dos parâmetros obtidas no primeiro passo foram consideradas como variáveis dependentes em um modelo ANOVA, sendo os tratamentos as combinações de genótipos e sexo.

Os códigos das rotinas implementadas no software R são de livre acesso em http://www.det.ufv. br/ moyses/links.php.

\section{RESULTADOS E DISCUSSÕES}

Na tabela 1, estão apresentadas, para cada modelo de crescimento considerado, as estimativas (média a posteriori) para os parâmetros populacionais $\mu_{\mathrm{A}}$ (peso adulto) e $\mu_{\mathrm{K}}$ (taxa de maturidade) em cada combinação dos níveis de sexo e genótipos do halotano. Também são apresentadas as estimativas das diferenças entre estes parâmetros para cada um destes grupos (combinações), bem como os intervalos HPDs obtidos. Nesta tabela, observa-se que, para os modelos Gompertz e Logístico, há uma diferença significativa entre a estimativa da média do peso adulto dos machos $\mathrm{Hal}^{\mathrm{Nn}}$ e machos $\mathrm{Hal}^{\mathrm{NN}}$, uma vez que o intervalo HPD para a diferença não contém o valor zero. Além disso, como essas diferenças são maiores que zero, conclui-se que o peso adulto dos machos $\mathrm{Hal}^{\mathrm{Nn}}$ é maior do que o peso adulto dos machos $\mathrm{Hal}^{\mathrm{NN}}$, uma vez que foram consideradas distribuições para a diferença $\mathrm{Hal}^{\mathrm{Nn}}-\mathrm{Hal}^{\mathrm{NN}}$. Para o modelo von Bertalanffy, não foram observadas diferenças significativas.

Por meio do teste de RAFTERY \& LEWIS (1992), pode-se dizer que a convergência foi atingida, pois o período de aquecimento (burn in), o número total de iterações e o intervalo entre as amostragens (thin) usados foram superiores ao mínimo recomendado por este teste. Além disso, todos os p-valores obtidos para o critério de GEWEKE (1992) indicaram convergência das cadeias, visto que $\mathrm{H}_{0}$ postula convergência, e esses p-valores variaram de 0,19 a 0,99 .

Sob o enfoque Bayesiano, para escolher o modelo que melhor descreveu o crescimento dos animais, foi utilizado o Deviance Information Criterion (DIC), o qual indicou o modelo Logístico,

Ciência Rural, v.44, n.10, out, 2014. 
Tabela 1 - Estimativas Bayesianas para os parâmetros dos modelos de crescimento e para as diferenças entre estas estimativas de cada grupo (combinação entre os níveis do fator sexo e genótipo do halotano) com os respectivos intervalos HPD de 95\%.

\begin{tabular}{|c|c|c|c|c|c|}
\hline \multirow{2}{*}{ Modelos } & \multirow{2}{*}{ Parâmetros } & \multirow{2}{*}{ Média } & \multirow{2}{*}{ Desvio padrão } & 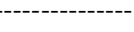 & 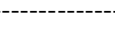 \\
\hline & & & & $\mathrm{LI}$ & LS \\
\hline \multirow{12}{*}{ Logístico } & $\mu_{\mathrm{AmNN}^{+}}$ & 81,03 & $6,60 \times 10^{-1}$ & 79,81 & 82,30 \\
\hline & $\mu_{\mathrm{AmNn}}$ & 83,84 & $6,79 \times 10^{-1}$ & 82,54 & 85,10 \\
\hline & $\mu_{\mathrm{AfNN}}$ & 79,75 & $4,18 \times 10^{-1}$ & 78,89 & 80,77 \\
\hline & $\mu_{\mathrm{AfNn}}$ & 80,36 & $8,28 \times 10^{-1}$ & 78,81 & 81,95 \\
\hline & $\mu_{\mathrm{KmNN}}$ & $3,28 \times 10^{-2}$ & $5,75 \times 10^{-4}$ & $3,17 \times 10^{-2}$ & $3,39 \times 10^{-2}$ \\
\hline & $\mu_{\mathrm{KmNn}}$ & $3,23 \times 10^{-2}$ & $1,45 \times 10^{-3}$ & $2,93 \times 10^{-2}$ & $3,50 \times 10^{-2}$ \\
\hline & $\mu_{\mathrm{KfNN}}$ & $3,32 \times 10^{-2}$ & $5,83 \times 10^{-4}$ & $3,20 \times 10^{-2}$ & $3,43 \times 10^{-2}$ \\
\hline & $\mu_{\mathrm{KfNn}}$ & $3,29 \times 10^{-2}$ & $1,16 \times 10^{-3}$ & $3,07 \times 10^{-2}$ & $3,52 \times 10^{-2}$ \\
\hline & $\mu_{\mathrm{AmNn}-} \mu_{\mathrm{AmNN}}$ & $3,71^{*}$ & $9,92 \times 10^{-1}$ & 1,84 & 5,72 \\
\hline & $\mu_{\mathrm{KmNn}}{ }^{-} \mu \mathrm{KmNN}$ & $-7,48 \times 10^{-4}$ & $1,56 \times 10^{-3}$ & $-3,25 \times 10^{-3}$ & $2,20 \times 10^{-3}$ \\
\hline & $\mu_{\mathrm{AfNn}}-\mu_{\mathrm{AfNN}}$ & $9,70 \times 10^{-1}$ & 1,02 & -1.05 & 2,92 \\
\hline & $\mu_{\mathrm{KfNn}}-\mu_{\mathrm{KfNN}}$ & $-3,60 \times 10^{-4}$ & $1,28 \times 10^{-3}$ & $-2,91 \times 10^{-3}$ & $2,12 \times 10^{-3}$ \\
\hline \multirow{12}{*}{ Gompertz } & $\mu_{\mathrm{AmNN}}^{+}$ & 137,46 & 1,08 & 135,80 & 139.80 \\
\hline & $\mu_{\mathrm{AmNn}}$ & 143,62 & 3,36 & 138,8 & 150,60 \\
\hline & $\mu_{\mathrm{AfNN}}$ & 138,39 & $7,94 \times 10^{-1}$ & 136,20 & 139.2 \\
\hline & $\mu_{\mathrm{AfNn}}$ & 138,52 & 3,01 & 132,40 & 144 \\
\hline & $\mu_{\mathrm{KmNN}}$ & $1,27 \times 10^{-2}$ & $6,96 \times 10^{-5}$ & $1,26 \times 10^{-2}$ & $1,29 \times 10^{-2}$ \\
\hline & $\mu_{\mathrm{KmNn}}$ & $1,2 \times 10^{-2}$ & $2,82 \times 10^{-3}$ & $1,19 \times 10^{-2}$ & $1,30 \times 10^{-2}$ \\
\hline & $\mu_{\mathrm{KfNN}}$ & $1,26 \times 10^{-2}$ & $6,77 \times 10^{-5}$ & $1,25 \times 10^{-2}$ & $1,28 \times 10^{-2}$ \\
\hline & $\mu_{\mathrm{KfNn}}$ & $1,19 \times 10^{-2}$ & $2,75 \times 10^{-4}$ & $1,15 \times 10^{-2}$ & $1,25 \times 10^{-2}$ \\
\hline & $\mu_{\mathrm{AmNn}-} \mu_{\mathrm{AmNN}}$ & $6,16^{*}$ & 3,52 & 0,7 & 13,60 \\
\hline & $\mu_{\mathrm{KmNn}}{ }^{-} \mu \mathrm{KmNN}$ & $-2,19 \times 10^{-4}$ & $2,90 \times 10^{-4}$ & $-8,1 \times 10^{-4}$ & $3,1 \times 10^{-4}$ \\
\hline & $\mu_{\mathrm{AfNn}}-\mu_{\mathrm{AfNN}}$ & 0,13 & 3,12 & $-6,0$ & 6.0 \\
\hline & $\mu_{\mathrm{KfNn}}-\mu_{\mathrm{KfNN}}$ & $-6,84 \times 10^{-4}$ & $2,84 \times 10^{-4}$ & $-1,23 \times 10^{-5}$ & $9 \times 10^{-3}$ \\
\hline \multirow{12}{*}{ von Bertalanffy } & $\mu_{\mathrm{AmNN}}{ }^{+}$ & 156,74 & 2,92 & 151,3 & 161,7 \\
\hline & $\mu_{\mathrm{AmNn}}$ & 159,21 & 3,08 & 153,3 & 165,6 \\
\hline & $\mu_{\mathrm{AfNN}}$ & 162,98 & 2,38 & 158,3 & 167,5 \\
\hline & $\mu_{\mathrm{AfNn}}$ & 159,63 & 4,84 & 150 & 168 \\
\hline & $\mu_{\mathrm{KmNN}}$ & $8,24 \times 10^{-3}$ & $1,57 \times 10^{-4}$ & $7,95 \times 10^{-3}$ & $8,54 \times 10^{-3}$ \\
\hline & $\mu_{\mathrm{KmNn}}$ & $8,55 \times 10^{-3}$ & $2,82 \times 10^{-4}$ & $7,99 \times 10^{-3}$ & $9,10 \times 10^{-3}$ \\
\hline & $\mu_{\mathrm{KfNN}}$ & $7,88 \times 10^{-3}$ & $1,34 \times 10^{-4}$ & $7,62 \times 10^{-3}$ & $8,15 \times 10^{-3}$ \\
\hline & $\mu_{\mathrm{KfNn}}$ & $8,03 \times 10^{-3}$ & $2,93 \times 10^{-4}$ & $7,46 \times 10^{-3}$ & $8,62 \times 10^{-3}$ \\
\hline & $\mu_{\mathrm{AmNn}}-\mu_{\mathrm{AmNN}}$ & 2,46 & 4,26 & $-5,7$ & 11 \\
\hline & $\mu_{\mathrm{KmNn}}{ }^{-} \mu \mathrm{KmNN}$ & $-3,14 \times 10^{-4}$ & $3,24 \times 10^{-4}$ & $-3,19 \times 10^{-4}$ & $9,48 \times 10^{-4}$ \\
\hline & $\mu_{\mathrm{AfNn}}-\mu_{\mathrm{AfNN}}$ & $-3,34$ & 5,37 & $-14,1$ & 6,7 \\
\hline & $\mu_{\mathrm{KfNn}}-\mu_{\mathrm{KfNN}}$ & $1,44 \times 10^{-4}$ & $3,22 \times 10^{-4}$ & $-4,93 \times 10^{-4}$ & $7,66 \times 10^{-4}$ \\
\hline
\end{tabular}

$+\mu_{\mathrm{AmNN}}, \mu_{\mathrm{AmNn}}, \mu_{\mathrm{AfNN}}, \mu_{\mathrm{AfNn}}$ representam, respectivamente, as estimativas do peso adulto para machos com genótipos HAL ${ }^{\mathrm{NN}}$ e com genótipos $\mathrm{HAL}^{\mathrm{Nn}}$; e para fêmeas com genótipos $\mathrm{HAL}^{\mathrm{NN}}$ e com genótipos HAL ${ }^{\mathrm{Nn}}$. Os termos $\mu_{\mathrm{KmNN}}, \mu_{\mathrm{KmNn}}, \mu_{\mathrm{KfNN}}$ e $\mu_{\mathrm{KfNn}}$ correspondem a estes mesmos grupos, porém para o parâmetro K (taxa de maturidade). * Significativo via HPD.

uma vez que este apresentou um menor DIC em todos os grupos considerados. Esse resultado está de acordo com o encontrado por FREITAS (2005), que, ao estudar sete modelos não-lineares, considerandose o ajuste de curvas de crescimento na produção animal, verificou que o modelo Logístico apresentou melhor ajuste para a maioria das espécies estudadas, dentre elas a suína. KUSEC et al. (2007), ao estudar suínos provenientes de diferentes cruzamentos, também apontaram para o modelo Logístico como sendo o mais adequado para descrever as curvas de crescimento dos animais.

Como o modelo Logístico foi o que melhor se ajustou aos dados, as estimativas dos 
parâmetros deste modelo foram utilizadas com a finalidade de avaliar a influência do gene halotano sobre a curva de crescimento dos animais. Desse modo, conforme mostrado na tabela 1 , conclui-se que o peso adulto dos suínos machos $\mathrm{Hal}^{\mathrm{Nn}}$ é maior do que o peso adulto dos suínos machos $\mathrm{Hal}^{\mathrm{NN}}$. Em contraste com este trabalho, BAND et al. (2005), ao avaliarem a influência do gene halotano sobre características de desempenho (pesos a diferentes idades, inclusive ao abate) em uma população de suínos F2, resultantes de cruzamentos divergentes (comercial x Piau), utilizando um modelo linear, concluíram que, para a maioria das características, não se observaram diferenças significativas entre os genótipos do halotano. Do mesmo modo, KUSEC et al. (2007) não encontraram diferenças significativas entre os genótipos do halotano sobre as estimativas dos parâmetros do modelo Logístico, considerando também dois regimes de alimentação (intensivo e restritivo). Na figura 1, está apresentada a densidade a posteriori para a diferença entre a estimativa da média do peso adulto de suínos machos com genótipo heterozigoto e homozigoto dominante $\left(\mu_{\mathrm{AmNn}}-\mu_{\mathrm{AmNN}}\right)$. Nota-se que o valor zero realmente encontra-se fora (à esquerda) do intervalo HPD de $95 \%$ para a diferença entre as médias do peso adulto, indicando que genótipos $\mathrm{HAL}^{\mathrm{Nn}}$ apresentam um maior peso à idade adulta.

$\mathrm{Na}$ abordagem Frequentista, após obter as estimativas individuais dos parâmetros dos modelos
Gompertz, Logístico e von Bertalanffy, estas foram consideradas como variáveis dependentes em um modelo linear (ANOVA), cujos níveis dos tratamentos foram as combinações entre os genótipos do gene halotano (com dois níveis, genótipos $\mathrm{Hal}^{\mathrm{NN}}$ e $\mathrm{Hal}^{\mathrm{Nn}}$ ) e sexo (com dois níveis, macho e fêmea). Ao contrário do resultado encontrado pela abordagem Bayesiana, na abordagem Frequentista, não foi possível detectar diferenças significativas entre as estimativas dos parâmetros em relação aos quatro grupos considerados (machos e fêmeas com diferentes genótipos), uma vez todos os $\mathrm{p}$-valores para o teste $\mathrm{F}$ foram maiores que 0,05 . Este resultado está de acordo com os resultados encontrados pelos autores citados anteriormente, os quais também se basearam em ANOVA para tirar as conclusões a respeito da influência do halotano sobre o crescimento de suínos. Nessa abordagem Frequentista, para escolher o modelo que melhor descreveu $o$ crescimento dos animais, utilizou-se o coeficiente de determinação $\left(\mathrm{R}^{2}\right)$ e o Critério de informação de Akaike (AIC). Nesta abordagem, também foi verificado que o modelo Logístico foi o que melhor se ajustou aos dados, pois este apresentou, respectivamente, maiores e menores valores para o $\mathrm{R}^{2}$ e AIC.

As médias das estimativas dos parâmetros do modelo Logístico, Gompertz e von Bertalanffy, as quais não diferiram estatisticamente entre grupos, estão apresentadas na tabela 2. Nesta tabela, nota-se ainda que a abordagem Frequentista superestimou as

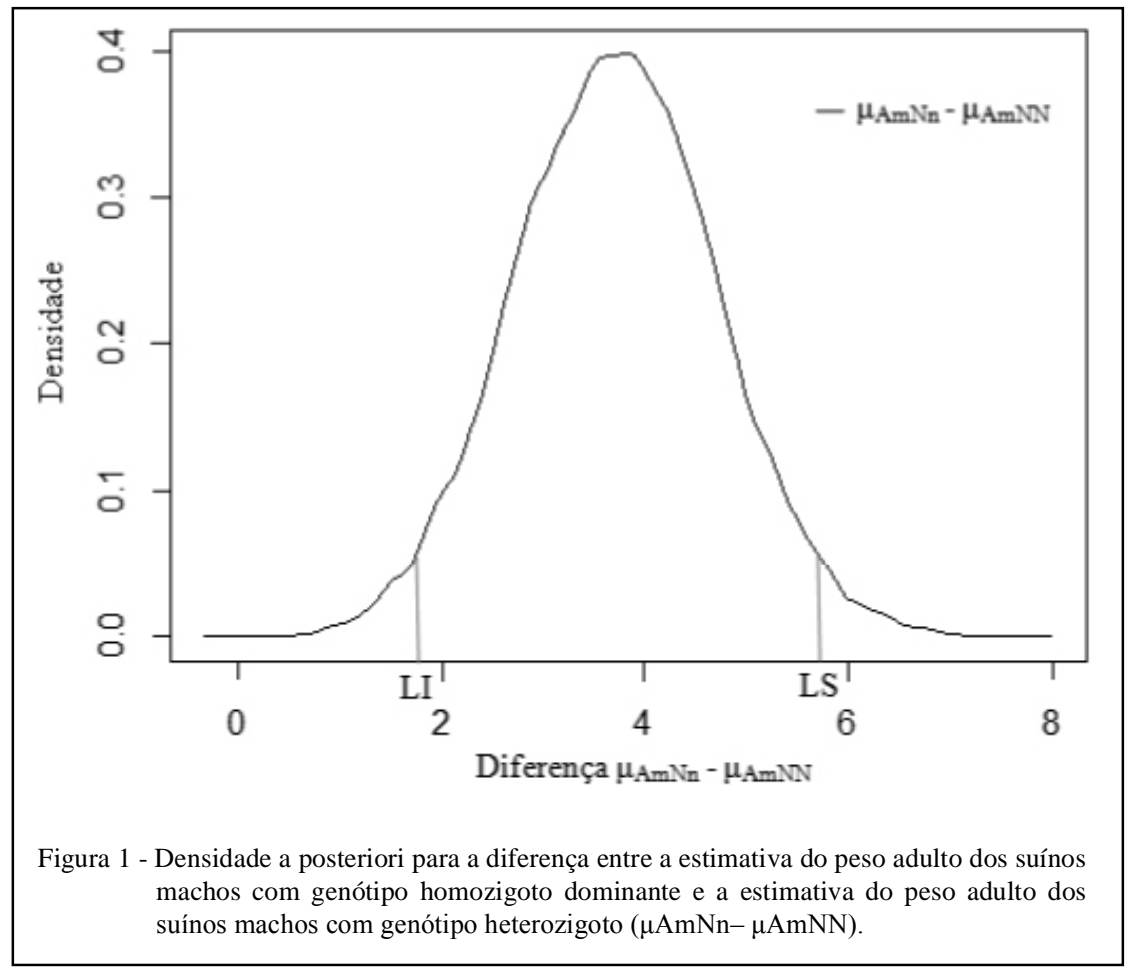

Ciência Rural, v.44, n.10, out, 2014. 
Tabela 2 - Média das estimativas dos parâmetros A (peso adulto) e K (taxa de maturidade), para os modelos Logístico, Gompertz e von Bertalanffy (abordagem Frequentista).

\begin{tabular}{|c|c|c|c|c|}
\hline Modelo & Grupo & Parâmetro & Média & Desvio padrão \\
\hline \multirow{8}{*}{ Logístico } & \multirow{2}{*}{ Macho HAL $^{\text {NN }}$} & A & 88,34 & 18,29 \\
\hline & & $\mathrm{K}$ & $3,20 \times 10^{-2}$ & $4,54 \times 10^{-3}$ \\
\hline & \multirow{2}{*}{ Macho HAL $^{\mathrm{Nn}}$} & A & 90,35 & 17,99 \\
\hline & & K & $3,02 \times 10^{-2}$ & $3,21 \times 10^{-3}$ \\
\hline & \multirow{2}{*}{ Fêmea HAL ${ }^{\mathrm{NN}}$} & A & 88,18 & 17,34 \\
\hline & & $\mathrm{K}$ & $3,18 \times 10^{-2}$ & $4,86 \times 10^{-3}$ \\
\hline & \multirow{2}{*}{ Fêmea HAL ${ }^{\mathrm{Nn}}$} & A & 89,70 & 20,10 \\
\hline & & K & $3,11 \times 10^{-2}$ & $3,86 \times 10^{-3}$ \\
\hline \multirow{8}{*}{ Gompertz } & \multirow{2}{*}{ Macho HAL ${ }^{\mathrm{NN}}$} & A & 211.59 & 150.29 \\
\hline & & $\mathrm{K}$ & $1,19 \times 10^{-2}$ & $4,12 \times 10^{-3}$ \\
\hline & \multirow{2}{*}{ Macho HAL $^{\mathrm{Nn}}$} & A & 224.94 & 186.02 \\
\hline & & $\mathrm{K}$ & $9,57 \times 10^{-3}$ & $2,41 \times 10^{-3}$ \\
\hline & \multirow{2}{*}{ Fêmea $\mathrm{HAL}^{\mathrm{NN}}$} & A & 208.97 & 037.23 \\
\hline & & $\mathrm{K}$ & $1,16 \times 10^{-2}$ & $4,25 \times 10^{-3}$ \\
\hline & \multirow{2}{*}{ Fêmea HAL ${ }^{\mathrm{Nn}}$} & A & 207.90 & 126.46 \\
\hline & & K & $1,12 \times 10^{-2}$ & $3,54 \times 10^{-3}$ \\
\hline \multirow{8}{*}{ von Bertalanffy } & \multirow{2}{*}{ Macho HAL $^{\text {NN }}$} & A & 320,12 & 209,57 \\
\hline & & $\mathrm{K}$ & $6,47 \times 10^{-3}$ & $2,98 \times 10^{-3}$ \\
\hline & \multirow{2}{*}{ Macho HAL $^{\mathrm{Nn}}$} & A & 358,55 & 207,11 \\
\hline & & $\mathrm{K}$ & $4,62 \times 10^{-3}$ & $1,34 \times 10^{-3}$ \\
\hline & \multirow{2}{*}{ Fêmea $\mathrm{HAL}^{\mathrm{NN}}$} & A & 347,33 & 216,88 \\
\hline & & $\mathrm{K}$ & $6,10 \times 10^{-3}$ & $3,04 \times 10^{-3}$ \\
\hline & \multirow{2}{*}{ Fêmea HAL ${ }^{\mathrm{Nn}}$} & A & 339,84 & 173,30 \\
\hline & & $\mathrm{K}$ & $5,76 \times 10^{-3}$ & $2,73 \times 10^{-3}$ \\
\hline
\end{tabular}

estimativas dos parâmetros das curvas de crescimento, principalmente para o peso adulto (A).

\section{CONCLUSÃO}

$\mathrm{O}$ modelo que melhor se ajustou aos dados apresentados neste trabalho foi o modelo Logístico, pois apresentou um melhor ajuste, tanto na abordagem Frequentista (via AIC e $\mathrm{R}^{2}$ ) quanto na Bayesiana (via DIC). Esta última abordagem mostrou-se mais apropriada para avaliar a influência do gene halotano sobre as curvas de crescimento dos animais, permitindo identificar que o genótipo $\mathrm{HAL}^{\mathrm{Nn}}$ exerce influência significativa apenas no peso adulto dos machos, sendo que estes apresentam peso superior àqueles de genótipo homozigoto.

\section{REFERÊNCIAS}

BAND, G.O. et al. Relationship between the Porcine Stress Syndrome gene and carcass and performance traits in F2 pigs resulting from divergent crosses. Genetics and Molecular Biology, v.28, n.1, p.92-96, 2005. Disponível em: <http://dx.doi. org/10.1590/S1415-47572005000100016>. Acesso em: 12 jan. 2013. doi:10.1590/S1415-47572005000100016
BLASCO, A et al. A Bayesian analysis of the effect of selection for growth rate on growth curves in rabbits. Genetic Selection Evolution, v.35,n p.21-41, 2003. Disponível em: <http://dx.doi. org/10.1051/gse:2002034>. Acesso em: 12 nov. 2012. doi: $10.1186 / 1297-9686-35-1-21$

BRIDI, A.M. et al. Efeito da ractopamina e do gênero no desempenho e na carcaça de suínos de diferentes genótipos halotano. Seminário de Ciências Agrárias, Londrina, v.29, n.3, p.713-722, 2008.

CULAU, P.O.V. et al. Influência do gene halotano sobre a qualidade da carne suína. Revista Brasileira de Zootecnia, v.31, p.954961, 2002. Disponível em: <http://dx.doi.org/10.1590/S151635982002000400019>. Acesso em: 10 dez. 2012. doi:10.1590/ S1516-35982002000400019.

FREITAS,A.R.de. Curvas de crescimentona produção animal. Revista Brasileira de Zootecnia, v.34, n.3, p.786-795, 2005. Disponível em: <http://dx.doi.org/10.1590/S1516-35982005000300010>. Acesso em: 2 nov. 2012. doi: 10.1590/S1516-35982005000300010.

FUJII, J. et al. Identification of a mutation in porcine ryanodine receptor associated with malignant hyperthermia. Science, v.253, n.2, p.448-451, 1991. Disponível em: 〈http://dx.doi.org/ 10.1126/science.1862346>. Acesso em: 15 nov. 2012. doi: 10.1126/science.1862346.

GEWEKE, J. Evaluating the accuracy of sampling-based approaches to calculating posterior moments. New York: Oxford University, 1992. 631p. 
KUSEC, G. et al. Influence of MHS genotype and feeding regime on allometric and temporal growth of pigs assessed by magnetic resonance imaging. Livestock Science, v.110, p.89-100, 2007. Disponível em: <http://dx.doi.org/10.1016/j.livsci.2006.10.007>. Acesso em: 7 out. 2012. doi: 10.1016/j.livsci.2006.10.007.

R DEVELOPMENT CORE TEAM. R: a language and environment for statistical computing. Vienna, Austria, 2012 ISBN 3-900051-07-0. Disponível em: <http://www.R-project. org/>. Online. Acesso em: 5 dez. 2012.

RAFTERY, A.E.; LEWIS, S. How many iterations in the gibbs sampler? In: BERNARDO, J.M. et al. (Eds.). Bayesian statistics. Oxford: University, 1992. p.763-773.

SATHER, A.P. et al. The effect of the halothane genotype on pork production and meat quality of pigs reared under commercia conditions. Canadian Journal of Animal Science, v.71, n.4, p.959967, 1991. Disponível em: 〈http://dx.doi.org/10.4141/cjas91-117〉. Acesso em: 29 set. 2012. doi: 10.4141/cjas91-117.

SILVA, F.F. et al. Abordagem Bayesiana da curva de lactação de cabras Saanen de primeira e segunda ordem de parto. Pesquisa agropecuária brasileira, v.40, n.1, p.2733, 2005. Disponível em: <http://dx.doi.org/10.1590/S0100204X2005000100004>. Acesso em: 15 nov. 2012. doi: 10.1590/ S0100-204X2005000100004.

SILVA, N.A.M. et al. Aplicação do método bayesiano na estimação de curva de Crescimento em animais da raça Nelore. Ceres, v.54, n.312, p.191-198, 2007. <http://www.redalyc.org/ articulo.oa?id=305226740005 $>$. Acesso em: 3 jan. 2013. doi: 305226740005 